\title{
Control algorithms for a Range Extender vehicle with an combustion engine
}

The combination of two drive sources: the internal combustion engine and the electric motor in the hybrid drive system requires an appropriate control system to manage their operation. It relies on many variables, and the greater the degree of drive hybridization the greater is the degree of interdependence of the parameters involved. The article presents solutions of electric drive control algorithms with an additional power source in the form of an internal combustion engine (Range Extender). The results of simulation analyzes in the AVL Cruise program are presented, taking into account three control algorithms and two driving cycles. The obtained results indicate the necessity to take various input quantities into account in order to optimize the use of the combustion engine.

Key words: control algorithms, Range Extender, electric motor, combustion engine, battery system

\section{Introduction}

Battery electric vehicles (BEV), at present, do not constitute a large group of vehicles in operation, due to their limited range. However, their share in the overall number of means of transport continues to increase [9]. A partial solution to the limited range problem is the use of range extender systems (REX or Range-Extended Electric Vehicle REEV) in the form of an internal combustion engine (coupled with an electric generator) or a fuel cell (producing electricity) to recharge the batteries [1]. Range extenders are built as series drivetrains in hybrid systems.

For longer distances, REVs utilize the ICE to keep the battery charged, but consume noticeably less fuel than conventional ICEVs for the following two reasons [4]:

- The engine of an E-REV is significantly smaller than that of a conventional ICEV - it only needs to meet average power demands because peak power is delivered by the battery pack. The engine of an ICEV, on the other hand, must also cover peak-power surges, e.g. acelerations.

- The engine of an E-REV operates at a constant, highly efficient, rotation speed; whereas that of an ICEV often runs at low or high rotation speeds during which, in both situations, its efficiency is low.

There are currently attempts to use microturbines [6] and Wankel engines powered by gasoline [14] or hydrogen [15] in range extender systems.

Traditional control of the battery charging system in hybrid drive systems (without plug-in technology) maintained a fairly narrow range of changes in the state of charge
(SOC). The use of a plug-in system increases the discharge range of the battery (Fig. 1), but at the same time requires the use of higher capacity batteries.

In such a system, the batteries can operate in two modes: typical discharge mode (CD - charge depleting) and sustained charge mode (CS - charge sustaining).

The first battery mode is applicable when the internal combustion engine is not used (driving in electric mode). The second mode, after discharging to the minimum value set by the controller, keeps the batteries low. This reduces the fuel consumption of the internal combustion engine, ensuring SOC values that are compatible with the combustion engine and the electric motor.

Thanks to the two operating modes, it is possible to use the available battery capacity to a greater extent, and the sustained battery charge level (DOD - depth on discharge) - much lower than in traditional hybrid drive systems.

\section{Range Extender drive system control conditions}

Controlling series hybrid drive systems (such as the REX drive) is much simpler than controlling a parallel or mixed hybrid drive. Currently, there are many methods used for controlling such systems. The simplest solution is to turn on the internal combustion engine within a certain range of battery SOC changes. In REX systems, high battery discharge is maintained in the CS - charge sustaining mode. The discharge value ranges from $25 \%$ to even $13 \%$ [5].

A simplified representation of such control was presented by Jeong [5], who divided the operating range into four modes:
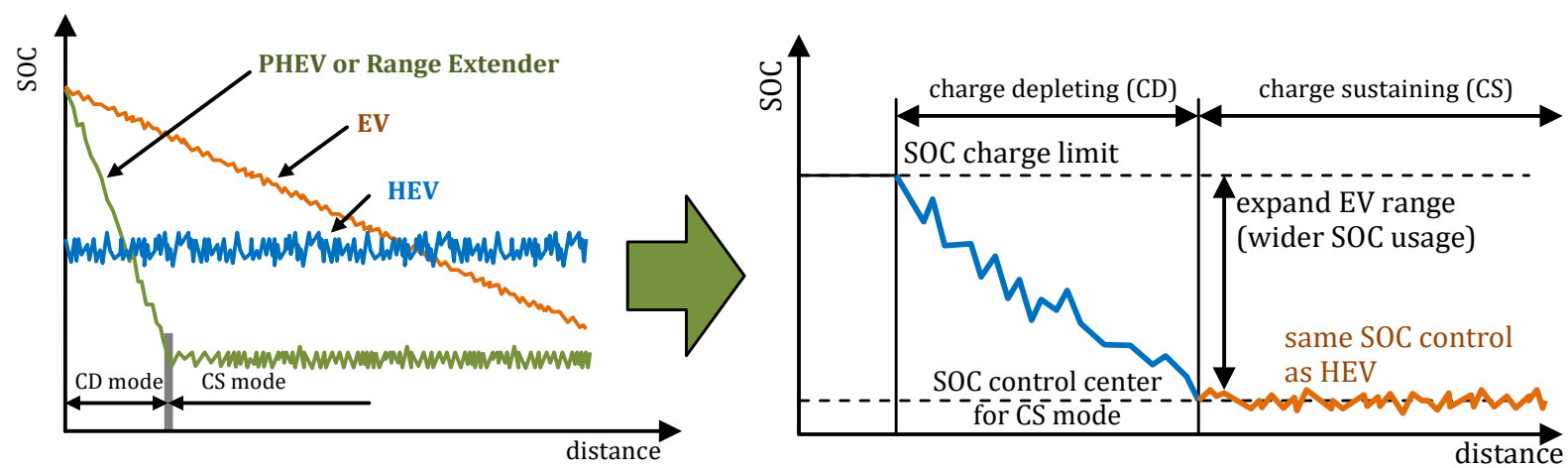

Fig. 1. Range Extender powertrain batteries discharge against purely electric (EV) and hybrid (HEV) drive modes [10, 13] 
1. Charge depletion - the range extender does not activate and the battery state of charge (SOC) is permitted to deplete without assistance except through brake regeneration.

2. Charge sustain - state of charge high.

3. Charge sustain - state of charge medium

4. Charge sustain - state of charge low.

Diversified SOC level (in the above operating ranges) leads to changes in the internal combustion engine operation: greater discharge results in increased engine speed and higher load values.

The analysis of the economic viability of the BMW i3 drive with an internal combustion engine system was conducted by Boretti [3]. Putting together several generations of the vehicle, the BMW i3 decided that the REX solution makes sense only when covering distances longer than the electric range. He showed that in the case of the BMW i3 $\mathrm{BEV}$, increasing the battery's electrical capacity by $1 \mathrm{Ah}$ translates into a range reduction of $0.88 \mathrm{~km}(0.55$ miles $)$ due to the increase in vehicle weight by $9.97 \mathrm{~kg}$. While equipping an internal combustion engine into the BMW i3 increases its weight by $122.5 \mathrm{~kg}$.

Although Range Extender drive systems have been available for several years, their operating strategies should still be verified. It is particularly important in the aspect of regenerative braking [7], as well as for the analysis of exhaust emissions and fuel consumption [8, 12].

\section{Research aim}

The analysis of the REX type drives presented in the article indicates their great diversity (in the form of the use of a battery and a secondary source of power, such as an internal combustion engine). The aim of this article is to determine the differences in the operating conditions of the internal combustion engine with the use of various control algorithms in various vehicle driving conditions.

\section{Method}

\subsection{Test vehicle}

The object of the research was a vehicle model whose characteristic parameters were presented in Table 1.

Table 1. Parameters characterizing the test vehicle with the internal combustion engine

\begin{tabular}{|l|c|c|}
\hline Parameter & Unit & Value \\
\hline Wheelbase & $\mathrm{mm}$ & 2467 \\
\hline Frontal surface & $\mathrm{m}^{2}$ & 1.97 \\
\hline Mass & $\mathrm{kg}$ & 1700 \\
\hline Combustion engine type & & $\begin{array}{c}\text { 3-cylinder SI, } \\
\text { naturally aspirated }\end{array}$ \\
\hline Fuel type & - & gasoline \\
\hline Stroke volume & $\mathrm{cm}^{3}$ & 800 \\
\hline Torque $-\mathrm{Mo}$ & $\mathrm{Nm} / \mathrm{rpm}$ & $95 / 4200$ \\
\hline Power $-\mathrm{Ne}$ & $\mathrm{kW} / \mathrm{rpm}$ & $51.4 / 5780$ \\
\hline
\end{tabular}

It was assumed that the vehicle drive system should meet the following assumptions:

1. Electric motor with a maximum torque of $240 \mathrm{Nm}$ at a rotational speed of $3000 \mathrm{rpm}$.

2. Generator adapted to work in line with the combustion engine: both with a torque of approximately $100 \mathrm{Nm}$ in the rotational range of 3000-4000 rpm. This was as- sumed as a rotational speed that allows applying a significant load on both the generator and the internal combustion engine.

A 3-cylinder combustion engine with a displacement of $800 \mathrm{~cm}^{3}$ was chosen, the characteristics of which are shown in Fig. 2. Additionally, the characteristics of the electric motor and generator were also presented in that figure.
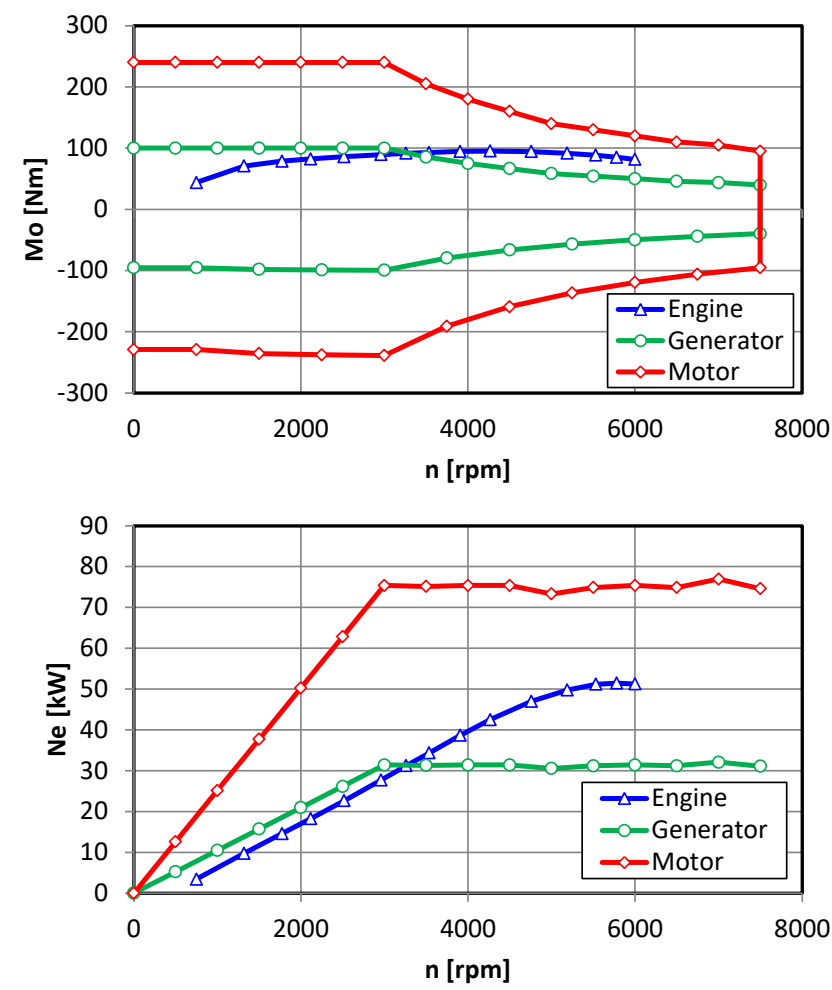

Fig. 2. Characteristics of the electric motor, generator and engine: a) torque, b) power

The selection of the battery was guided by the analysis of modern solutions used in such systems. Several batteries were analyzed from among which Li-Ion LNMCO cells $\left(\mathrm{LiNi}_{1} / 3 \mathrm{Mn}_{1} / 3 \mathrm{Co}_{1} / 3 \mathrm{O}_{2}\right.$ - Lithium-Nickel-Mangan-Cobalt) [16] with parameters presented in Table 2 were selected.

Table 2. Technical parameters of the LNMCO batteries

\begin{tabular}{|l|c|c|}
\hline Parameter & Unit & Value \\
\hline Max charge & $\mathrm{Ah}$ & 30 \\
\hline Nominal voltage & $\mathrm{V}$ & 3.7 \\
\hline Maximum voltage & $\mathrm{V}$ & 4.15 \\
\hline Minimum Voltage & $\mathrm{V}$ & 3.4 \\
\hline Number of cells per row & pcs. & 80 \\
\hline Number of cells rows & pcs. & 1 \\
\hline $\begin{array}{l}\text { Internal charge/discharge } \\
\text { resistance }\end{array}$ & mOhm & $1.5 / 1.4$ \\
\hline
\end{tabular}

\subsection{Driving cycles}

Research analyzes on the use of the internal combustion engine (and its operating conditions) were carried out using two standardized routes:

- in a NEDC test,

- in a WLTC test.

Characteristic parameters of these research tests were provided in Table 3 . 


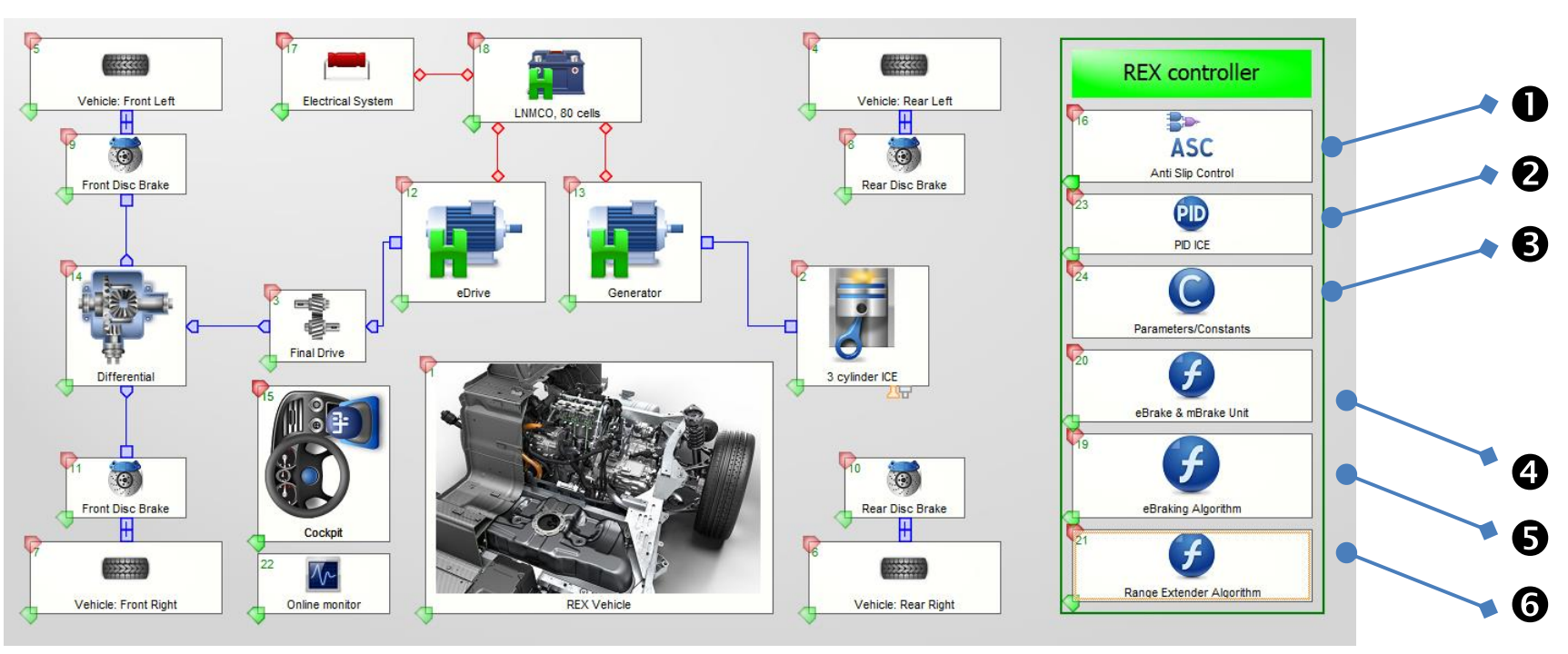

Fig. 3. Schematics of the analyzed REX type drive system

Table 3. Comparison of research tests used in simulations [11]

\begin{tabular}{|l|c|c|}
\hline Parameter & NEDC Test & WLTC Test \\
\hline Test cycle & Single test cycle & Dynamic cycle \\
\hline Cycle time & $1180 \mathrm{~s}$ & $1800 \mathrm{~s}$ \\
\hline Cycle distance & $11 \mathrm{~km}$ & $23.25 \mathrm{~km}$ \\
\hline Average speed & $34 \mathrm{~km} / \mathrm{h}$ & $46.5 \mathrm{~km} / \mathrm{h}$ \\
\hline Maximum speed & $120 \mathrm{~km} / \mathrm{h}$ & $131 \mathrm{~km} / \mathrm{h}$ \\
\hline Driving phases & $\begin{array}{c}2 \text { phases, } 66 \% \text { urban, } \\
34 \% \text { non-urban } \\
\text { driving }\end{array}$ & $\begin{array}{c}4 \text { phases, } \\
52 \% \text { urban, } \\
46 \% \text { non-urban }\end{array}$ \\
\hline
\end{tabular}

\section{Simulation model and REX drive system control}

The REX drive simulation tests were carried out using the AVL Cruise software [2]. The program implements individual elements of the Range Extender drive system, assigning appropriate functions to the mechanical and electrical elements included in the simulation. Visualization of the mechanical and electrical diagram is shown in Fig. 3.

In addition to the typical elements of the drive system also the parameters controlling such a system were considered (shown in Fig. 3 on the right).

- Anti Slip Control (ASC) system. The system controls wheel slip by adjusting the torque value on each wheel separately. At first, the wheel with the highest value for the load transmitting factor $\left(\mathrm{T}_{\mathrm{F}}\right)$ is selected.

$$
\mathrm{T}_{\mathrm{F}}=\frac{\mathrm{F}_{\mathrm{L}}}{\mu \cdot \mathrm{F}_{\mathrm{N}}}
$$

where: $F_{L}-$ driving force, $F_{N}-$ downwards force, $\mu$ - friction coefficient.

If this value greater than 1 , the anti-slip control is activated and the load position will be reduced as long as the wheels have slip conditions (Fig. 4).

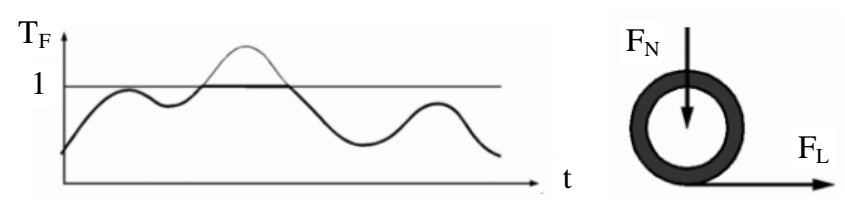

Fig. 4. Load transmission factor [2]
(2) Internal combustion engine PID controller (PID ICE). It is a regulator system that adjusts the changes in the engine speed to the set values.

The difference between target value and actual value is calculated by

$$
\Delta \mathrm{C}=\mathrm{C}_{\mathrm{PID}, \mathrm{des}}-\mathrm{C}_{\mathrm{PID}, \mathrm{act}}
$$

If there is a limitation of the actual value by definition of a lower limit, the sign of $\Delta \mathrm{C}$ is changed.

The controller output is defined by

$$
\begin{gathered}
\mathrm{C}_{\text {PID,out }}=\mathrm{C}_{\text {PID.P }} \cdot \Delta \mathrm{C}+ \\
+\mathrm{C}_{\text {PID.I }} \cdot \int_{0}^{\mathrm{t}} \Delta \mathrm{C}(\mathrm{t}) \mathrm{dt}+ \\
+\mathrm{C}_{\text {PID.D }} \cdot \frac{\mathrm{d}(\Delta \mathrm{C})}{\mathrm{dt}}
\end{gathered}
$$

In the current example: $\mathrm{P}=10 ; \mathrm{I}=0 \mathrm{~s} ; \mathrm{D}=1 \mathrm{e}-4 \mathrm{~s}^{-1}$, thus

$$
\mathrm{C}_{\text {PID,out }}=\mathrm{C}_{\text {PID.P }} \cdot \Delta \mathrm{C}+\mathrm{C}_{\text {PID.D }} \cdot \frac{\mathrm{d}(\Delta \mathrm{C})}{\mathrm{dt}}
$$

3 Parameters/Constants. The module contains values that limit process variables or typical constant values. There are, among others, quantities determining the battery state of charge (SOC), maximum pressure in the braking system and braking coefficients (front - BFF; rear - BFR) constituting a component of the braking torque:

$$
\begin{gathered}
\mathrm{M}_{\mathrm{B}}=2 \mathrm{p}_{\mathrm{B}} \cdot \mathrm{A}_{\mathrm{B}} \cdot \eta_{\mathrm{B}} \cdot \mu_{\mathrm{B}} \cdot \mathrm{r}_{\mathrm{B}} \cdot \mathrm{c}_{\mathrm{B}} \\
\mathrm{BFF}=2 \cdot \mathrm{A}_{\mathrm{BF}} \cdot \eta_{\mathrm{BF}} \cdot \mu_{\mathrm{BF}} \cdot \mathrm{r}_{\mathrm{BF}} \cdot \mathrm{c}_{\mathrm{BF}} \\
\mathrm{BFR}=2 \cdot \mathrm{A}_{\mathrm{BR}} \cdot \eta_{\mathrm{BR}} \cdot \mu_{\mathrm{BR}} \cdot \mathrm{r}_{\mathrm{BR}} \cdot \mathrm{c}_{\mathrm{BR}}
\end{gathered}
$$

where: $p_{B}$ - braking system pressure, $A_{B}$ - the brake cylinder area; the area of the hydraulic cylinder (front $-A_{B}=$ $=1800 \mathrm{~mm}^{2}$; rear $-A_{B}=1500 \mathrm{~mm}^{2}, \eta_{B}-$ the efficiency considers the effects of the conversion of the hydraulic into the mechanical part of the brake $\left(\eta_{B}=0.99\right), m_{B}-$ the friction coefficient is between the brake drum, and respectively the friction disc or the brake shoes $\left(m_{B}=0.25\right), r_{B}$ - the radius where the braking force applies (front $-r_{B}=130$ $\mathrm{mm}$; rear $\left.-\mathrm{r}_{\mathrm{B}}=110 \mathrm{~mm}\right), \mathrm{c}_{B}-$ the specific brake factor is 
a factor that depends on the design of the brake (disc brakes $\mathrm{c}_{\mathrm{B}}=1$; drum brakes $\mathrm{c}_{\mathrm{B}}>1$ ).

An overview of the values indicated above is presented in Table 4.

Table 4. Examples of values of parameters and constants

\begin{tabular}{|l|c|c|c|}
\hline Parameter & Value & Unit & $\begin{array}{c}\text { Method of } \\
\text { determination }\end{array}$ \\
\hline $\begin{array}{l}\text { Brake factor front } \\
\text { (BFF) }\end{array}$ & 0.00011583 & - & Equation (6) \\
\hline $\begin{array}{l}\text { Brake factor rear } \\
(\mathrm{BFR})\end{array}$ & 0.000081675 & - & Equation (7) \\
\hline $\mathrm{SOC}_{\min }$ & 13.5 & $\%$ & $\begin{array}{c}\text { Taken } \\
\text { arbitrarily }\end{array}$ \\
\hline $\mathrm{SOC}_{\max }$ & 16.0 & $\%$ & $\begin{array}{c}\text { Taken } \\
\text { arbitrarily }\end{array}$ \\
\hline $\begin{array}{l}\mathrm{Max}_{\text {brake pressure }} \\
\left(\mathrm{BP}_{\max }\right)\end{array}$ & 50 & bar & Taken from [2] \\
\hline
\end{tabular}

4 eBrake \& mBrake Unit. The algorithm determines the conditions for the transition from eDrive to eBrake (Front \& Rear). When calculating the braking torque of the electric motor $\left(\mathrm{M}_{\mathrm{EM}}\right)$, one should take into account the gear ratio in the main gear $\left(i_{\mathrm{FD}}=6.21\right)$ as well as the gear ratio in the gearbox (not present in this case; $i_{G}=1$ ). Determining from equation (5) and using the $\mathrm{i}_{\mathrm{FD}}$ gear ratio the current pressure in the brake system is calculated as:

$$
\mathrm{p}_{\mathrm{B}}=\frac{\mathrm{M}_{\mathrm{EM}} \cdot \mathrm{i}_{\mathrm{FD}} \cdot \mathrm{i}_{\mathrm{G}}}{2 \mathrm{p}_{\mathrm{B}} \cdot \mathrm{A}_{\mathrm{B}} \cdot \eta_{\mathrm{B}} \cdot \mu_{\mathrm{B}} \cdot \mathrm{r}_{\mathrm{B}} \cdot \mathrm{c}_{\mathrm{B}}}
$$

and taking the indicators of BFF (equation (6)) and BFR (equation (7)) as the sum of the braking coefficients:

$$
p_{B}=\frac{M_{E M} \cdot i_{F D}}{B F F+B F R} \text {. }
$$

the equivalent of the pressure in the braking system is obtained, which can be converted into electric braking (energy recuperation). If electric motor braking is used, then $\mathrm{p}_{B}$ (i.e. eBrake) takes negative values (negative torque value). In this case, electric braking will be used first, and if the braking performance requires additional pressures, then braking with the use of the hydraulic system will take place. If $\mathrm{M}_{\mathrm{EM}}>0$, this motor transmits positive torque to the wheels of the vehicle.

5 eBraking Algorithm. The algorithm determines the conditions for the transition from eDrive to eBrake. The necessary condition for the use of regenerative braking is the simultaneous fulfillment of two relationships (increase in pressure in the brake system and vehicle speed above a certain value):

Brake Pressure $>0$ and Vehicle velocity $>0.1 \mathrm{~km} / \mathrm{h}$

In this case, braking is initiated, the control signal of which (activating the hydraulic braking) is defined as the ratio of the current brake pressure - BR to the maximum system pressure $\mathrm{BR}_{\max }$ :

$$
\mathrm{y}=\frac{\mathrm{BR}}{\mathrm{BR}_{\max }}
$$

(6) Range Extender Algorithm. The last part of the REX drive control system concerns the algorithms for determining the internal combustion engine start-up algorithm. Three internal combustion engine operation algorithms have been implemented in the simulation program:
1. enabling the combustion engine to be started at one chosen operating point $(\mathrm{n}=3000 \mathrm{rpm}$ and $\mathrm{Mo}=0.6$ $\mathrm{Mo}_{\max }$ ) whenever the battery discharge level reaches the value of $\mathrm{SOC}_{\mathrm{act}}<\mathrm{SOC}_{\text {min }}$; charging ends after reaching $\mathrm{SOC}_{\max }$

2. taking into account the first case, but also including the shutdown of the internal combustion engine, when the drive system experiences zero load (vehicle braking and no-load operation, such as at standstill);

3. algorithm depending on battery SOC and vehicle speed: after achieving $\mathrm{SOC}_{\mathrm{act}}<\mathrm{SOC}_{\min }$ the internal combustion engine operating conditions depend on the vehicle speed: based on three speed ranges (the boundary points between these ranges are at $20 \mathrm{~km} / \mathrm{h}$ and $70 \mathrm{~km} / \mathrm{h}$ ); for which the internal combustion engine load changes at constant rotational speed, to $0.4 ; 0.6$ and $0.8 \mathrm{Mo}_{\max }$.

The block diagram of these algorithms is shown in Fig. 5.

Additionally, in order to secure a significant decrease in the battery SOC, a critical SOC restriction has been established. If the $\mathrm{SOC}_{\mathrm{cr}}<13 \%$ condition is met, the combustion engine will also be started: for mode 1 and 2 with standard settings, for mode 3 - the maximum settings contained in Fig. 5.

\section{Testing the control algorithms in driving tests}

\subsection{Battery operating conditions and the function of the drive system control algorithms}

The drive system tests were carried out on two test routes: for NEDC and WLTC.

By using a Li-Ion battery it becomes possible for the system to work in both CD and CS mode (shown in Fig. 1). The battery discharge (CD) mode is typical for electric vehicles. The study analyzed the battery recharging in the CS mode, therefore the initial value of the battery charge level was set at $15 \%$. It is a value between $\mathrm{SOC}_{\min }$ and $\mathrm{SOC}_{\max }$. The conditions of the algorithms' operation cause the recharging to start when the charge level drops below the minimum value.

\subsection{Drive system operating conditions}

The preliminary analysis of the test routes showed a much higher dynamics in the drive parameters in the WLTC test than in the NEDC test (Fig. 6). With similar maximum speeds in both tests, the typical NEDC acceleration was $0.7-1 \mathrm{~m} / \mathrm{s}^{2}$ (maximum $-1.1 \mathrm{~m} / \mathrm{s}^{2}$ ) - Fig. 6a. In the WLTC test, the maximum acceleration was slightly lower, amounting to $0.9-1 \mathrm{~m} / \mathrm{s}^{2}$. This was reflected in the operating conditions of the electric (drive) motor. In the NEDC test, the maximum torques were higher (up to $150 \mathrm{Nm}$, with $\mathrm{M}_{\text {omax }}=$ $=240 \mathrm{Nm}$ ) compared to the WLTC test (up to $100 \mathrm{Nm}$ ). However, the dynamics of torque value changes was greater during the WLTC test (Fig. 6b). Characteristically, during the regenerative braking, similar loads were obtained in both tests (about $75 \mathrm{Nm}$ ). In the WLTC test, speed values above $70 \mathrm{~km} / \mathrm{h}$ were much more frequent than in the NEDC test, which indicates that the proposed drive system control algorithms should have a greater relevance in this test.

Data presented in Fig. 7 confirmed the presence of higher engine load values in the NEDC test. The electric motor worked in the first quadrant of the Mo-n characteristic, as a current generator - in the second quadrant. The 


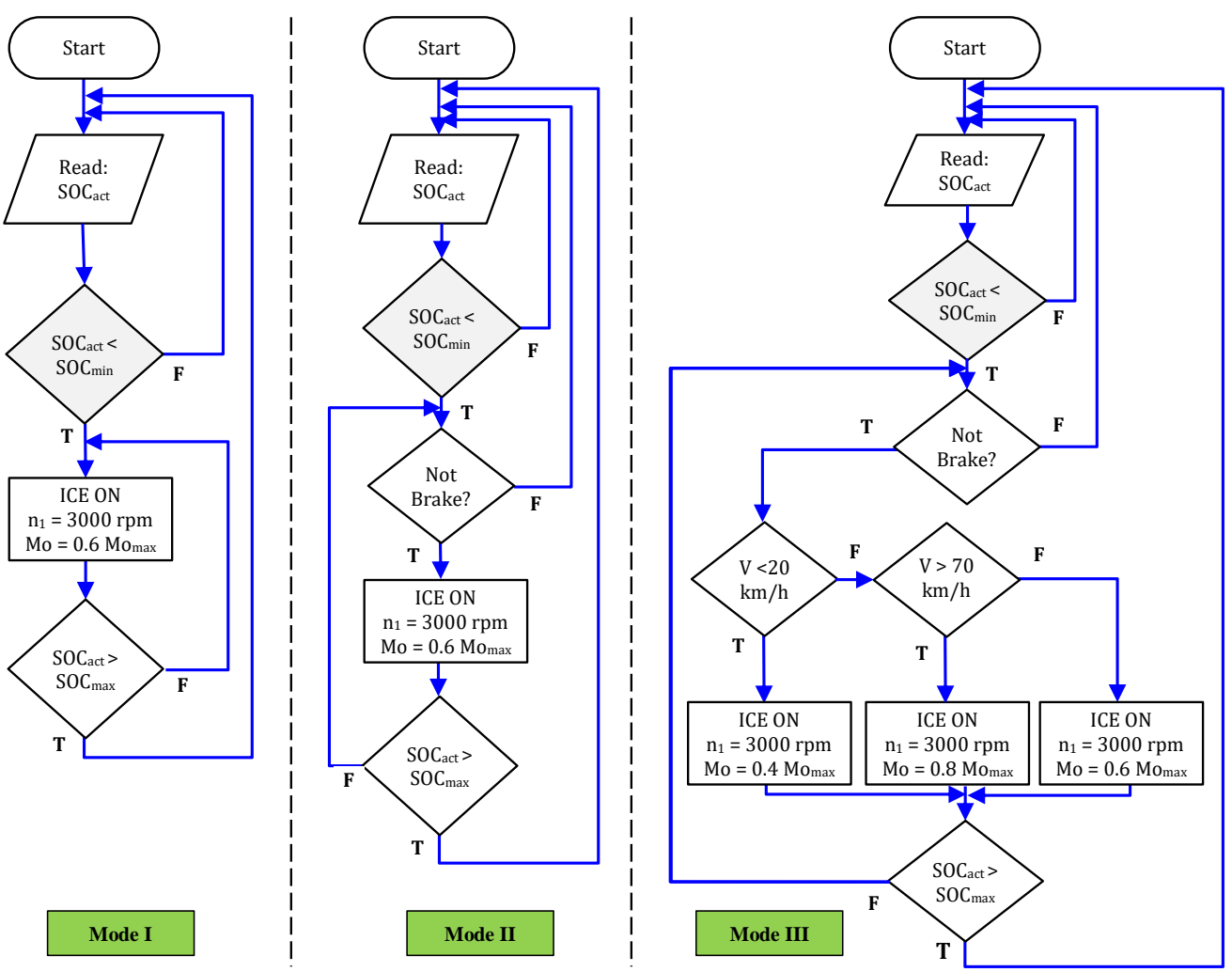

Fig. 5. The adopted control algorithms for the REX drive system

a)

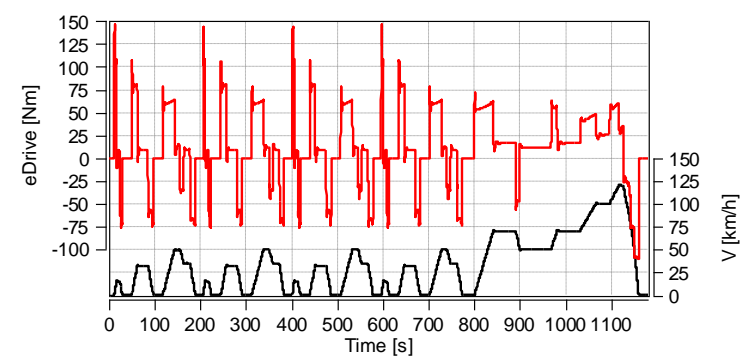

b)

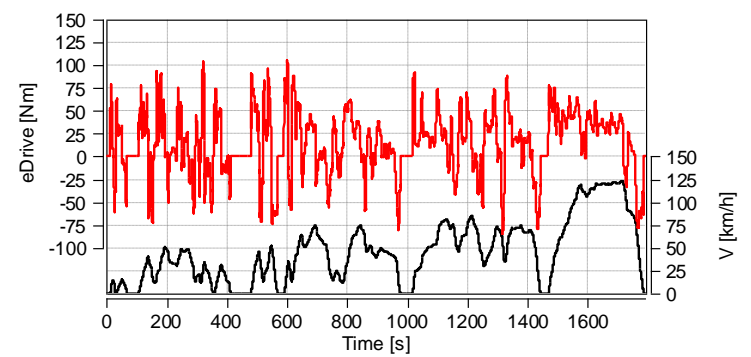

Fig. 6. The electric drive motor torque and vehicle speed characteristics obtained in the tests: a) NEDC, b) WLTC

density of this engine's operating points in the WLTC test (Fig. 7b) showed significantly greater changes in its operation than in the NEDC test. Additionally, the adopted characteristics of the motor indicated that its use is in the efficiency range below $90 \%$. This may indicate increased battery power consumption values. It follows that in selected tests the used combustion engine was too big (in terms of its torque and power). Operation of the vehicle in real conditions may result in the engine working within its high a)

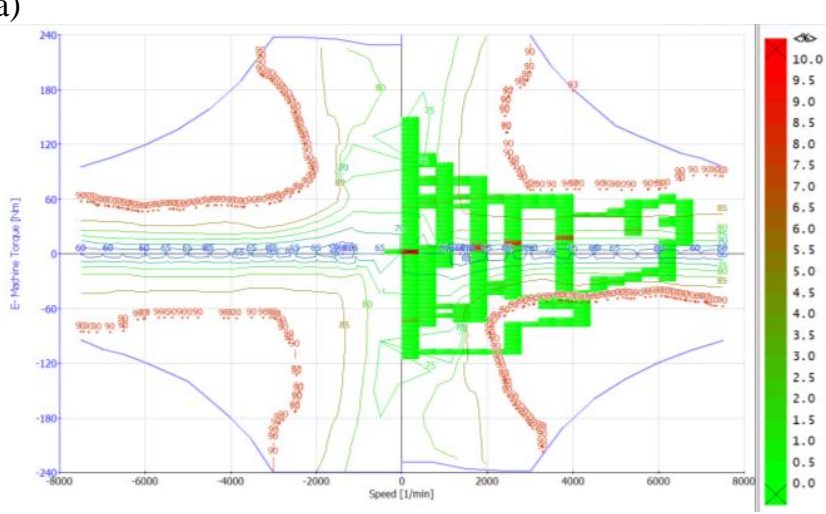

b)

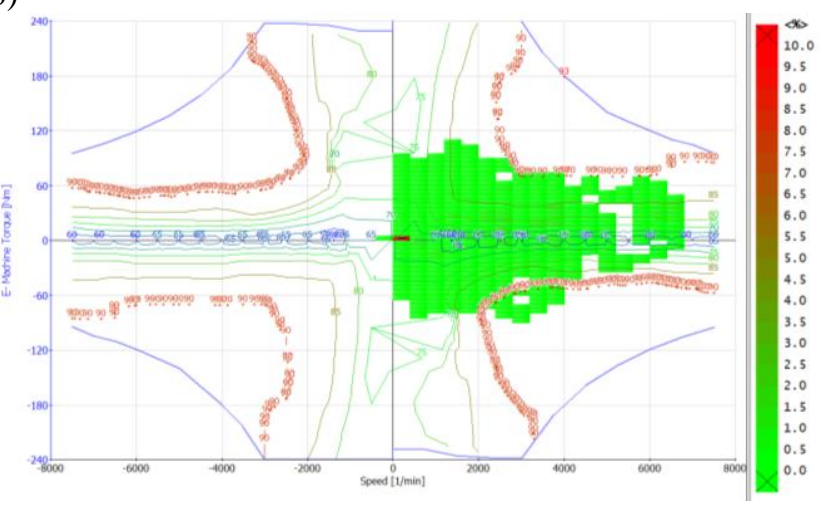

Fig. 7. Electric motor load : a) in the NEDC test, b) in the WLTC test

efficiency range. In both cited cases, the use of the braking torque in the efficiency range above $90 \%$ was observed, 
which should indicate energy recovery with high efficiency of the engine's operation as a generator.

\subsection{Comparative analysis of vehicle energy consumption}

\section{NEDC test}

The following aspects were analyzed in the simulation: SOC, electric motor power, electric energy consumption and signals of the generator load (relative load) coupled with the internal combustion engine.

SOC analysis shows charging to $\mathrm{SOC}_{\max }=15 \%$ in the case of the first algorithm (mode I). As a result, the combustion engine was still running despite braking (Fig. 8). This indicates using the full allowable SOC range. However, the disadvantage of this solution was the much longer single use of the internal combustion engine.

The modified algorithm (mode II) contains a function that allows turning the internal combustion engine off when $\mathrm{SOC}_{\mathrm{act}}>\mathrm{SOC}_{\min }$ and vehicle braking occurs. Then the SOC does not need to reach the $\mathrm{SOC}_{\max }$. This means that regenerative braking takes priority over the operation of the internal combustion engine. On the other hand, such a strategy caused the actual battery charge range to decrease and the internal combustion engine had to operate more often. Such conditions could also be observed in Fig. 8, when the internal combustion engine was used much more often than during the operation in mode I.

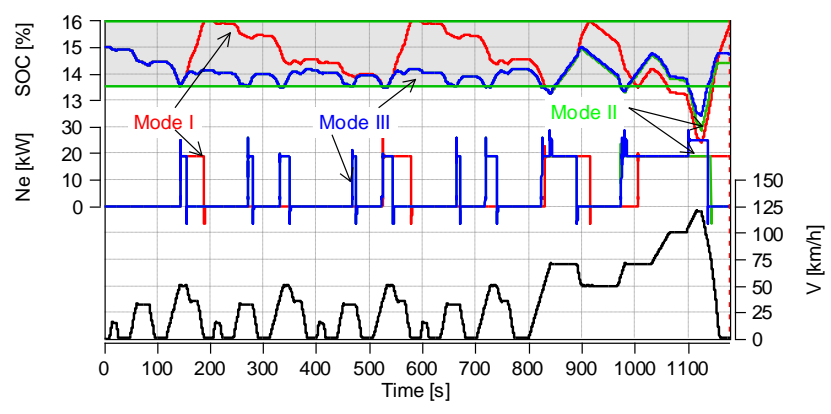

Fig. 8. Changes in SOC and internal combustion engine power in the NEDC test

Mode III places a differential load values on the internal combustion engine and the power generator during battery charging. As shown in Fig. 5, these values depend on the vehicle speed. This has a bearing on the discharge rate of the battery. Due to the low speed obtained during braking with the vehicle in the NEDC test, the first variant was practically not observed (low load of the combustion engine and generator at speeds below $20 \mathrm{~km} / \mathrm{h}$ ). However, in the case of high speed in this test, the use of an increased load on the battery charging system (internal combustion engine and generator) was observed in the final part of the test. Despite the different charging strategies, a significant drop in SOC at high driving speeds was observed. The introduced limitation in the form of SOC $<13 \%$ (which caused the combustion engine to always be on) - did not meet the conditions of maintaining SOC at the level of $13 \%$. This was a result of, among others, the high energy consumption and different operating conditions of the internal combustion engine and generator in this respect (control mode I and II do not apply varied load values to the internal combustion engine).
Analyzing the current flow and electric energy consumption, a significant recharging of the battery was observed during the operation of the internal combustion engine, taking into account the first mode (red curve - electrical consumption - in Fig. 9). Where negative consumption values indicate current generation. This value was about $0.1 \mathrm{kWh}$ and occurred in three instances of the combustion engine operation. Although a fourth such occurrence for the combustion engine begins to take place at $\mathrm{t}=$ $=1010 \mathrm{~s}$, the demand was not compensated by the operation of the engine. Only after starting braking at $125 \mathrm{~km} / \mathrm{h}$, the increased recharge of the battery was observed. This means that such an approach, despite the initial recharging, does not provide an effective solution for ensuring a sufficient battery charge level.

Due to the only slightly differentiated algorithms of modes II and III, the NEDC test lacks significant changes in battery charging. The differences are discernable only at the end of the NEDC test.

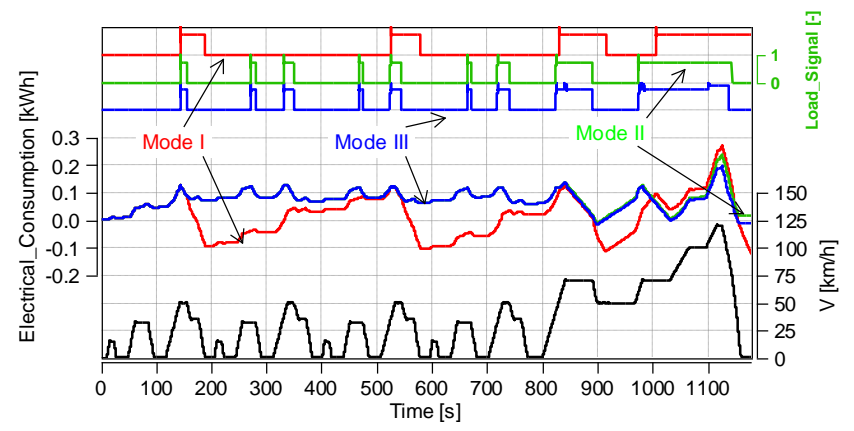

Fig. 9. Internal combustion engine load and electric energy consumption in the NEDC test

A summary of the above analyzes was reflected in the summary of SOC changes in the entire test (Table 5). It takes into account the battery charge limits in the NEDC test. The comparison shows that neither of the strategies was effective in reducing the battery energy level drop in the case of high driving speeds (related to high energy demand of the drive system). However, the smallest changes (the smallest SOC value drops) could be observed when using the algorithm in which the generator load keeps up with the changes in the battery SOC. In the case of mode I, a large SOC "margin" was obtained, but the fall below the critical value was also the largest. This means large fluctuations in the SOC value, which can significantly shorten the battery lifespan.

Table 5. SOC changes in the NEDC test in terms of different drive system control algorithms

\begin{tabular}{|l|c|c|c|}
\hline \multirow{2}{*}{ Value } & \multicolumn{3}{|c|}{ SOC [\%] } \\
\cline { 2 - 4 } & Mode I & Mode II & Mode III \\
\hline Min & 11.36 & 11.87 & 12.40 \\
\hline Mean & 14.60 & 13.98 & 14.02 \\
\hline Max & 16.00 & 15.00 & 15.02 \\
\hline
\end{tabular}

\section{WLTC test}

The conditions in the WLTC test were slightly different from the NEDC test, which should result in different SOC changes of the battery using different charging strategies. 
Despite similar maximum speeds in the WLTC test, the profile of the entire test was more diverse. This resulted in the internal combustion engine being started much more often (Fig. 10).

Determination of SOC changes within the range $\langle 13.5 ; 16\rangle$, indicates full utilization of this range only when using the algorithm of mode I. Using other algorithms, the battery SOC does not exceed about $15 \%$. With mode I, the battery is charged only a few times throughout the WLTC test.

In other strategies, the use of the internal combustion engine was much more frequent. In the case of modes II and III, the changes in the middle and final parts of the test were much greater. This means that the SOC changes in the case of modes II and III were also greater. High driving speeds in the final part of the test have resulted in a different use of the internal combustion engine. The control algorithm III is much more effective than the others in terms of limiting the drop in the battery SOC.

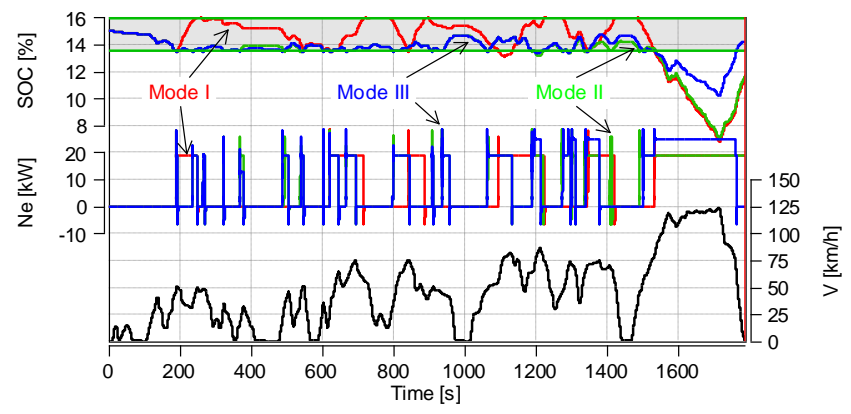

Fig. 10. Changes in SOC and internal combustion engine power in the WLTC test

The assessment of energy consumption (Fig. 11) shows high similarities of the energy flow compared to the NEDC test. However, the analysis of the IC engine load signal (Load_signal) shows its greater variability. Due to greater diversification of the driving profile, when the battery was recharged with the internal combustion engine on, the energy supplied to the battery reached the level of $0.2 \mathrm{kWh}$ This is approximately $100 \%$ more than in the NEDC test.

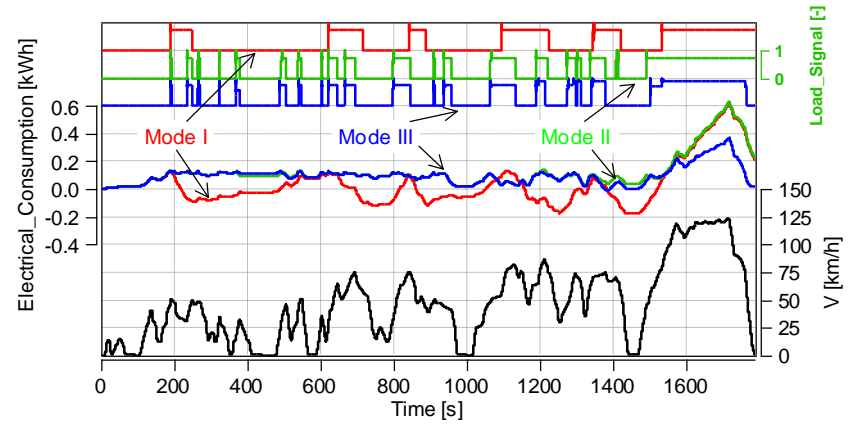

Fig. 11. Internal combustion engine load and electric energy consumption in the NEDC test

A comprehensive analysis of SOC changes in the WLTC test (Table 6) indicates a greater maximum discharge of the battery. With the control algorithms I and II, the obtained SOC had a minimum value of about $7 \%$. This means it exceeded the critical value $\left(\mathrm{SOC}_{\mathrm{cr}}=13 \%\right)$ by about $50 \%$. Such a drop in SOC value is very dangerous for the battery as it may lead to damage. The use of the third strategy results in the minimum SOC being around $10 \%$. This is approximately only $30 \%$ below the critical level.

Table 6. SOC changes in the WLTC test in terms of different drive system control algorithms

\begin{tabular}{|l|c|c|c|}
\hline \multirow{2}{*}{ Value } & \multicolumn{3}{|c|}{ SOC [\%] } \\
\cline { 2 - 4 } & Mode I & Mode II & Mode III \\
\hline Min & 6.77 & 7.00 & 10.15 \\
\hline Mean & 14.22 & 13.37 & 13.68 \\
\hline Max & 16.51 & 15.00 & 15.00 \\
\hline
\end{tabular}

The comparison of the effectiveness of the REX drive control algorithms in the NEDC and WLTC tests was provided in Fig. 12. It shows that the simplest algorithms work quite well in the range of low maximum speeds. This was due to the limited energy required to drive the vehicle. The final SOC value in all control cases was above the critical minimum value $\left(\mathrm{SOC}_{\mathrm{cr}}=13 \%\right)$.

However, the simplest algorithms caused the critical SOC value to be dangerously exceeded during testing. This was more prominent when using the simpler system control algorithms (regardless of the drive test). Increasing the maximum speeds with a limited energy capacity of the battery requires using more complex control algorithms. The most advanced system presented in the paper allowed for a significant reduction of the battery SOC drop (regardless of the drive test). In the case of the NEDC test, the $\mathrm{SOC}_{\mathrm{cr}}$ was exceeded by about $4 \%$ (which was qualified as being within the permissible error margin), while in the WLTC test - about $22 \%$.

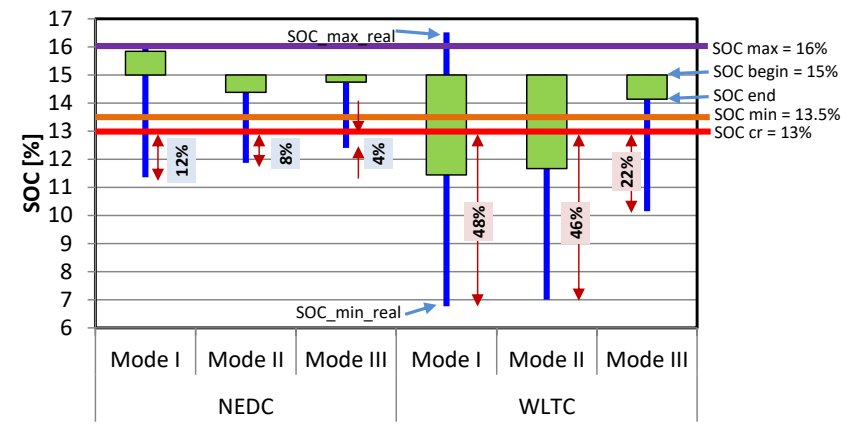

Fig. 12. Comparison of control algorithms in the Range Extender system in the two research tests

\section{Conclusion}

The presented research results of the control algorithms in the Range Extender drive system make it possible to draw the following conclusions:

1. The energy recovery systems and the conditions of cooperation between the internal combustion engine and the battery with different control algorithms for REX systems were successfully analyzed.

2. The control algorithms that take into account only the SOC limit values, do not properly control the battery charge in dynamic tests. It can only be effective under steady driving conditions or when driving in urban conditions while not reaching travel speeds over $80 \mathrm{~km} / \mathrm{h}$.

3. Using algorithms that use feedback from changes in the battery SOC allows for effective reduction of the range 
of SOC changes. The advantage of such algorithms is that they keep the SOC in the acceptable range even during tests at higher driving speeds.

4. Using algorithms that take into account the thermal management of the internal combustion engine and various operating conditions of the internal combustion engine (rotational speed and load) could effectively enable predicting the energy flow changes in the battery sys- tem. At the same time, it can be used to avoid the state of "deep discharge", thus increasing the lifespan and durability of the whole system.

\section{Acknowledgements}

This work has been done under AVL University Partnership Program.

\section{Nomenclature}

CD charge depleting

CS charge sustaining

EV electric vehicle

REEV range-extended electric vehicle

HEV hybrid electric vehicle

NEDC New European Driving Cycle

REX range extender
WLTC World Harmonized Light Vehicle Test Cycle

Indexes

cr critical

min minimum

$\max$ maximum

act actual

\section{Bibliography}

[1] ANDWARI, A.M., PESIRIDIS, A., RAJOO, S. et al. A review of battery electric vehicle technology and readiness levels. Renewable and Sustainable Energy Reviews. 2017, 78, 414-430.

https://doi.org/10.1016/j.rser.2017.03.138

[2] AVL Cruise 2020 R1, User Manual. AVL 2020.

[3] BORETTI, A. Electric vehicles with small batteries and high-efficiency on-board electricity production. Energy Storage. 2019, 1, e75. https://doi.org/10.1002/est2.75

[4] DELL, R.M., MOSELEY, P.T., RAND, D.A.J. Progressive Electrification of Road Vehicles (chapter 5). Towards Sustainable Road Transport. Academic Press 2014, 157-192. https://doi.org/10.1016/B978-0-12-404616-0.00005-0

[5] JEONG, J., LEE, W., KIM, N. et al. Control analysis and model validation for BMW i3 range extender. SAE Technical Paper 2017-01-1152. 2017.

https://doi.org/10.4271/2017-01-1152

[6] JI, F., ZHANG, X., DU, F. et al. Experimental and numerical investigation on micro gas turbine as a range extender for electric vehicle. Applied Thermal Engineering. 2020, 173, 115236. https://doi.org/10.1016/j.applthermaleng.2020.115236.

[7] KROPIWNICKI, J., FURMANEK, M. Analysis of the regenerative braking process for the urban traffic conditions. Combustion Engines. 2019, 178(3), 203-207. https://doi.org/10.19206/CE-2019-335

[8] LIJEWSKI, P., KOZAK, M., FUĆ, P. et al. Exhaust emissions generated under actual operating conditions from a hybrid vehicle and an electric one fitted with a range extender. Transportation Research Part D: Transport and Environment. 2020, 78, 102183.

https://doi.org/10.1016/j.trd.2019.11.012

[9] MACIEJEWSKA, M., FUĆ, P., KARDACH, M. Analysis of electric motor vehicles market. Combustion Engines. 2019, 179(4), 169-175. https://doi.org/10.19206/CE-2019-428

[10] NEMRY, F., LEDUC, G., MUÑOZ, A. Plug-in hybrid and battery-electric vehicles: State of the research and development and comparative analysis of energy and cost efficien-

cy. Joint Research Centre. Institute for Prospective Technological Studies. Luxembourg 2009.

ftp://ftp.jrc.es/pub/EURdoc/JRC54699_TN.pdf

[11] Regulation (EU) 2017/1151 Supplementing Regulation (EC) No 715/2007 of the European Parliament and of the Council on type-approval of motor vehicles with respect to emissions from light passenger and commercial vehicles (Euro 5 and Euro 6) and on access to vehicle repair and maintenance information, amending Directive 2007/46/EC of the European Parliament and of the Council, Commission Regulation (EC) No 692/2008 and Commission Regulation (EU) No 1230/2012 and repealing Commission Regulation (EC) No 692/2008.

https://eur-lex.europa.eu/legalcontent/EN/TXT/?uri=CELEX\%3A32017R1151

[12] SOLOUK, A., TRIPP, J., SHAKIBA-HERFEH, M. et al. Fuel consumption assessment of a multi-mode low temperature combustion engine as range extender for an electric vehicle. Energy Conversion and Management. 2017, 148, 1478-1496. https://doi.org/10.1016/j.enconman.2017.06.090

[13] TAKAOKA, T., ICHINOSE, H. The newly developed Toyota plug-in hybrid system. 31. Internationales Wiener Motorensymposium 2010. Wien 2010.

[14] TURNER, M., TURNER, J., VORRARO, G. Mass benefit analysis of 4-stroke and Wankel range extenders in an electric vehicle over a defined drive cycle with respect to vehicle range and fuel consumption. SAE Technical Paper 2019-011282. 2019. https://doi.org/10.4271/2019-01-1282

[15] ZAMBALOV, S.D., YAKOVLEV, I.A., MAZNOY, A.S. Effect of multiple fuel injection strategies on mixture formation and combustion in a hydrogen-fueled rotary range extender for battery electric vehicles. Energy Conversion and Management. 2020, 220, 113097. https://doi.org/10.1016/j.enconman.2020.113097

[16] ZHANG, C., JIANG, J., ZHANG, L. et al. A generalized SOC-OCV model for lithium-ion batteries and the SOC estimation for LNMCO battery. Energies. 2016, 9, 900. https://doi.org/10.3390/en9110900

Prof. Ireneusz Pielecha, DSc., DEng. - Faculty of Civil and Transport Engineering, Poznan University of Technology.

e-mail: ireneusz.pielecha@put.poznan.pl

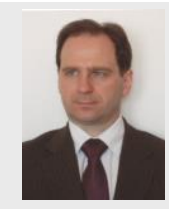

